\title{
Prevalence of hepatitis B, C, and HIV among patients attending a teaching dental hospital
}

\author{
A 7-year retrospective study from the United Arab Emirates
}

Subail H. Al-Amad, DClinDent, FRACDS (OralMed).

\section{ABSTRACT}

الأهداف: تحديد الانتشار المصلي وخصائص الحالات المصابة

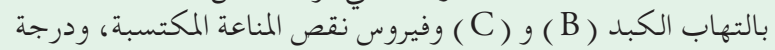

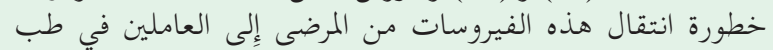

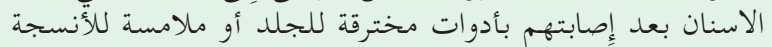
الطلائية والجلدَية.

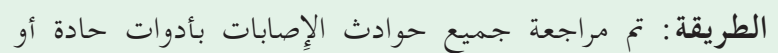

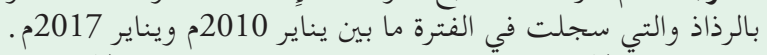

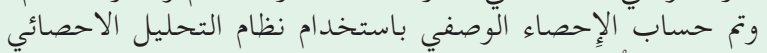

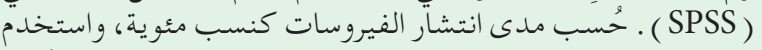

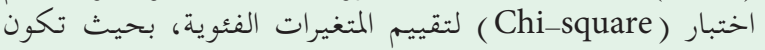

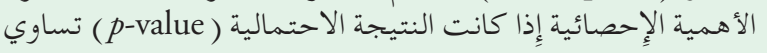
أو تقل عن 0.05.

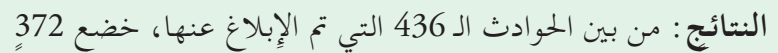

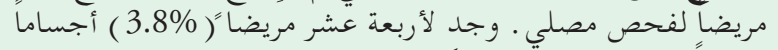

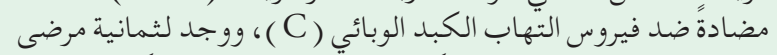

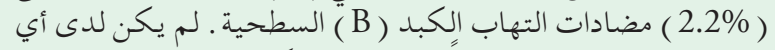

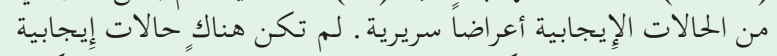

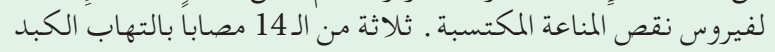

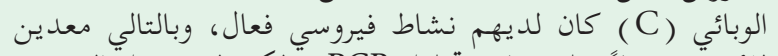

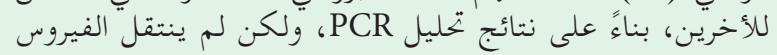

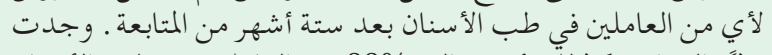

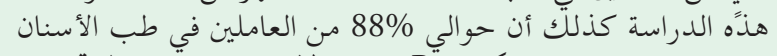

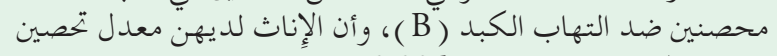

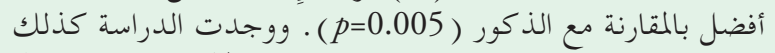

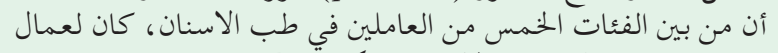
النظافة أقل معدل تطعيم لالتهاب الكبد" (B (B) ) (

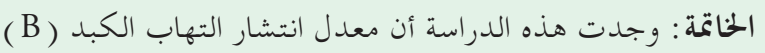

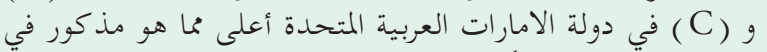

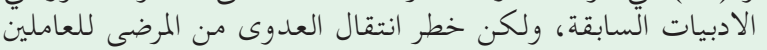

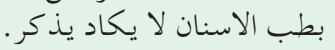

Objectives: To determine the seroprevalence and case characteristics of hepatitis B, C and human immunodeficiency virus (HIV), and their transmissibility from patients to dental personnel following percutaneous and mucocutaneous injuries.

Methods: All incidents of sharp and splash injuries reported between January 2010 and January 2017 were retrospectively reviewed and analyzed. Descriptive statistics were calculated using the Statistical Package for the Social Science (SPSS). Prevalence was calculated as percentages, and chi-square test was used to assess categorical variables where a $p$-value of $\leq 0.05$ was considered significant.

Results: Among the 436 reported incidents, 372 patients underwent serological screening. Fourteen patients $(3.8 \%)$ had antibodies against hepatitis $\mathrm{C}$ virus, and 8 patients $(2.2 \%)$ were positive for hepatitis B surface antigens. All positive cases were clinically asymptomatic. There were no positive cases for HIV. Three of the 14 hepatitis C positive patients were actively infectious upon polymerase chain reaction (PCR) analysis, but none of the injured dental personnel seroconverted upon a 6-month follow up. Approximately $88 \%$ of dental personnel were vaccinated against hepatitis $\mathrm{B}$. Female personnel showed better vaccination rate by comparison to male personnel $(p=0.005)$. Among the 5 different categories of professional status, cleaners showed a significantly low hepatitis B vaccination rate $(p<0.000)$.

Conclusion: The prevalence of hepatitis B and C is higher than that previously reported from the United Arab Emirates, but transmissibility of viral hepatitis seems to be negligible.

Saudi Med J 2018; Vol. 39 (5): 500-505 doi: 10.15537/smj.2018.5.22116

From the College of Dental Medicine, University of Sharjah, Sharjah, United Arab Emirates.

Received 23rd January 2018. Accepted 19th March 2018.

Address correspondence and reprint request to: Dr. Suhail H. Al-Amad, Associate Professor, College of Dental Medicine, University of Sharjah, Sharjah, United Arab Emirates.E-mail: salamad@sharjah.ac.ae ORCID ID: orcid.org/0000-0001-8872-4887 
T he global prevalence of hepatitis $\mathrm{B}$ virus (HBV) is $3.5 \%$ and hepatitis $\mathrm{C}$ virus (HCV) is $1 \%{ }^{1}$ However, this prevalence shows a marked variation between different regions in the world and between countries within the same region. For example, while the prevalence of HBV is less than $1 \%$ in North America, it exceeds $8 \%$ in Africa. ${ }^{2}$ A similar variation is observed in the prevalence of $\mathrm{HCV}$, which ranges from less than $1.5 \%$ in pacific Asia and North America to more than $3.5 \%$ in the Middle East and North Africa. ${ }^{3}$ In the Arabian Gulf countries, the prevalence is estimated to be $1.5 \% .{ }^{4}$ However, this prevalence varies significantly between 2 major groups of the population: citizens and expatriates. In the United Arab Emirates (UAE), the prevalence of HCV among nationals is $0.24 \%$ while it is $1.64 \%$ among expatriates. ${ }^{4}$ Several studies found that receiving dental treatment was a risk factor to the high prevalence of HBV and HCV. ${ }^{5-9}$ Patientto-patient transmission of $\mathrm{HBV}$ has been reported in dental clinics with inadequate infection control practices. ${ }^{10-12}$ Unsafe injections in healthcare settings, particularly in developing countries, were found to be a significant factor in the transmission of $\mathrm{HBV}, \mathrm{HCV}$ and human immunodeficiency virus (HIV). ${ }^{13,14}$ This study aims to determine the prevalence of HBV, HCV and HIV among dental patients who had been involved in incidents of percutaneous and mucocutaneous injuries at a dental hospital in the UAE, as well as the dental personnel's $\mathrm{HBV}$ vaccination rate. The study also aims to report on the post-exposure seroconversion of dental personnel who had sustained those injuries from positive patients.

Methods. This is a retrospective study which took place at the University Dental Hospital Sharjah (UDHS) and the College of Dental Medicine, University of Sharjah, United Arab Emirates. Inclusion criteria comprised of all cases of percutaneous (sharp and bite) injuries and mucocutaneous (splash) injuries that occurred between January 2010 and January 2017. Variables with missing data related to the vaccination status of dental personnel, or to the serological status of patients, were reported as descriptive results, but excluded from further statistical analysis. University Dental Hospital Sharjah is a modern purpose-built dental teaching hospital which encompasses 114 dental

Disclosure. Authors have no conflict of interests, and the work was not supported or funded by any drug company. chairs and receives approximately 20,000 patients every year. The hospital is owned and managed by the University of Sharjah.

Incident forms detailing the circumstances of each percutaneous and mucocutaneous injury were completed by the injured provider and included information about the provider's professional status (for instance, student, intern, clinician, nurse or cleaner), personal details of the patient, the mechanism of the injury and the instrument which caused it. Percutaneous injuries were defined as visible blood appearing on the skin following penetration by a sharp tool that is not sterile, or that is suspected of not being sterile. Mucocutaneous injuries were defined as aerosols that came in contact with the clinicians' facial mucosal surfaces (for instance, eyes, nasal cavity and/or oral cavity) while treating a patient or cleaning used instruments.

Incident forms also contained the results of screening tests related to the patient and to the dental healthcare provider. Results for the patient were for hepatitis B surface antigens ( $\mathrm{HBsAg}$ ), hepatitis C antibodies (HCV-Ab) and HIV antibodies (HIV-Ab). Dental personnel's test results were for hepatitis $\mathrm{B}$ antibody titer. All tests were performed using Electrochemiluminescence (Roche Diagnostics, USA). Positive results were repeated for confirmation by a reference lab. Patients who were positive for HCV-Ab were recalled to quantitatively determine viral RNA load using real-time polymerase chain reaction (RT-PCR).

Providers who were injured by positive patients were tested for the 3 viruses to establish an infection-free status around the time of injury, and then were followed up at 6 weeks, 3 months and 6 months after exposure to detect seroconversion.

Descriptive statistics were calculated using the Statistical Package for the Social Science (SPSS) Version 24.0 (IBM Corp., Armonk, NY, USA). Chi-square test was used to assess categorical variables where a $p$-value of $\leq 0.05$ was considered significant.

This research was approved by the University of Sharjah Research and Ethics Committee No. DFCM/16/11/14/121.

Results. Between January 2010 and January 2017, the infection control committee at UDHS received 436 incident reports of percutaneous and mucocutaneous injuries, with an average of 54.5 incidents per year. Three hundred and seventy-two patients underwent serological screening for $\mathrm{HBV}, \mathrm{HCV}$ and HIV. The remaining 64 incidents were not tested either because the source patient was not known (for instance, incidents occurred while cleaning multiple instruments 
Table 1 - Seroprevalence of hepatitis B, hepatitis C, and HIV.

\begin{tabular}{lrc}
\hline Screening test & $\mathbf{n}$ & $(\%)$ \\
\hline Hepatitis B surface antigen & 8 & $(2.2)$ \\
Hepatitis C antibodies & 14 & $(3.8)$ \\
HIV antibodies & 0 & $(0.0)$ \\
Negative for all three viruses & 350 & $(94.1)$ \\
Unknown* & 64 & - \\
\hline \multicolumn{3}{c}{ HIV - human immunodificiency virus, } \\
*Screening was not performed if the patient (or guardian, in case of \\
pediatric patients) did not consent for the serology tests, or if the injury \\
was related to an unknown source (while cleaning instruments). \\
\hline
\end{tabular}

Table 2 - Demographic and injury characteristics of patients who were found positive for $\mathrm{HBsAg}$.

\begin{tabular}{lcccc}
\hline Gender & Age & Nationality & $\begin{array}{c}\text { The instrument that } \\
\text { caused the injury }\end{array}$ & $\begin{array}{c}\text { HBsAb titer of } \\
\text { the injured dental } \\
\text { personnel }\end{array}$ \\
\hline Male & 36 & Pakistan & Scaler tip & $>1000$ \\
Male & 46 & Pakistan & Irrigation needle & 128 \\
Male & 47 & Pakistan & Irrigation needle & $>1000$ \\
Male & & Unknown & Splash & $>1000$ \\
Male & 46 & Pakistan & Irrigation needle & $>1000$ \\
Male & 62 & Pakistan & Blade & $>1000$ \\
Male & 28 & Uganda & Irrigation needle & $>1000$ \\
Male & 35 & Bangladesh & Probe & $>1000$ \\
\hline \multicolumn{4}{l}{ HBsAb - hepatitis B antibodies; HBsA - hepatitis B surface antigens }
\end{tabular}

from various patients) ( $\mathrm{n}=35)$, or because the patient or guardian did not consent to having those tests performed $(n=29)$. Among the tested patients, 8 were positive for $\mathrm{HBsAg}(2.2 \%)$ and 14 patients were positive for HCV-Ab (3.8\%). All patients were clinically asymptomatic. No coinfection between $\mathrm{HBV}$ and $\mathrm{HCV}$ was found. Antibodies against HIV were negative for all screened patients (Table 1).

All HBsAg positive patients were males with an average age of 42.6 years (Table 2). No further tests were performed for those patients because all the providers involved in those incidents had protective antibody titers against $\mathrm{HBV}$.

Twelve of the $14 \mathrm{HCV}$-Ab positive patients (85.7\%) were males with an average age of 47.4 years and 2 were females with an average age of 58 years. Patients positive for HCV antibodies belonged to 7 nationalities, but the majority were Egyptians and Pakistanis (Table 3). Follow up qualitative polymerase chain reaction (PCR) detected viral RNA in 3 patients, all of whom were males with an average age of 49 and belonged to one nationality (Egypt). Two patients who were positive for HCV antibodies did not consent to undertake PCR.
Providers who had been injured by HCV-RNA positive patients, or by patients who were $\mathrm{HCV}-\mathrm{Ab}$ positive and did not consent to undertake the PCR test, were followed up with 3 serological screenings after 1 month, 3 months, and 6 months, and showed no seroconversion.

Most of the incidents were caused by sharp dental instruments $(\mathrm{n}=401,92 \%)$, followed by splash injuries $(\mathrm{n}=24,5.5 \%)$ and bite injuries $(\mathrm{n}=3,0.7 \%)$. Seventyseven percent of injuries occurred while dental personnel were performing clinical operative work, while $22 \%$ of the injuries occurred while cleaning instruments. The majority of the injured dental personnel (76.6\%) were under training (students, interns and residents). Most of the injured dental healthcare providers were successfully vaccinated against hepatitis B by having protective antibody levels (Table 4). In comparison to male personnel, female personnel showed better vaccination rate, which was statistically significant $(p=0.005)$. Among the 5 different categories of professional status, cleaners showed a significantly low hepatitis B vaccination rate $(p<0.000)$.

Discussion. Globally, there are approximately 257 million people infected with HBV and 71 million people infected with HCV. ${ }^{1}$ Studies from countries such as Ethiopia, Egypt, Morocco, Turkey and Italy found a relatively high prevalence of $\mathrm{HBV}$ and $\mathrm{HCV}$ that was attributed to risk factors, one among which was dental treatment. ${ }^{5-9}$

Overall, there was an increase in HCV prevalence in most regions of the world from $2.3 \%$ in 1990 to $2.8 \%$ in $2005 .^{3}$ This prevalence was highest in countries in the Middle East and North Africa reaching up to $3.7 \% .^{3}$ Mohamoud et $\mathrm{al}^{4}$ reported that the prevalence of $\mathrm{HCV}$ among all residents in the UAE was $1.64 \%$. However, a significant difference between citizens and expatriates was shown, in which citizens had a prevalence of only $0.2 \%{ }^{4}$

The prevalence of HCV in this study is $3.8 \%$, which is higher than that previously reported. ${ }^{4}$ This can be attributed to the population presented here which consists of patients from countries known to have a high prevalence of HCV. For example, 39\% of the patients with positive HCV antibodies were Egyptians and 23\% were Pakistanis. All patients with PCR-positive HCV-RNA (0.8\%) were Egyptians. This is consistent with the global prevalence of $\mathrm{HCV}$, which shows that central Asia and the Middle East have the highest prevalence of HCV, with Egypt being the country with the biggest contribution to $\mathrm{HCV}$ prevalence among all Middle Eastern countries. ${ }^{3}$ 
Table 3 - Demographic and injury characteristics of patients who were found positive for HCV-Ab and HCV-RNA during post-exposure screening.

\begin{tabular}{|c|c|c|c|c|c|}
\hline Gender & Age & Nationality & Instrument which caused the injury & PCR & Follow up results of the injured dental personnel \\
\hline M & Unknown & Egypt & Local anesthesia needle & Positive & No seroconversion after 6 months \\
\hline M & 43 & Egypt & Unknown & Negative & \\
\hline M & 51 & India & Orthodontic wire & Negative & \\
\hline M & 63 & Pakistan & Endodontic file & Negative & \\
\hline M & Unknown & Bangladesh & Drilling bur & Not performed* & No seroconversion after 6 months \\
\hline M & 31 & Sudan & Irrigation needle & Negative & \\
\hline $\mathrm{F}$ & 63 & Syria & Local anesthesia needle & Negative & \\
\hline M & Unknown & Jordan & Local anesthesia needle & Negative & \\
\hline M & 46 & Egypt & Irrigation needle & Positive & No seroconversion after 6 months \\
\hline M & 52 & Egypt & Irrigation needle & Positive & No seroconversion after 6 months \\
\hline M & 53 & Egypt & Wax knife & Negative & \\
\hline $\mathrm{F}$ & 53 & Pakistan & Scaler tip & Negative & \\
\hline M & 31 & Pakistan & Elevator & Negative & \\
\hline M & 57 & Egypt & Elevator & Negative & \\
\hline
\end{tabular}

Table 4 - Characteristic of the injured dental personnel and the circumstances of their injuries.

\begin{tabular}{|c|c|c|}
\hline Category & $\mathrm{n}$ & $(\%)$ \\
\hline \multicolumn{3}{|l|}{ Dental personnel's gender } \\
\hline Male & 88 & $(20.2)$ \\
\hline Female & 348 & $(79.8)$ \\
\hline \multicolumn{3}{|l|}{ Dental personnel's professional status } \\
\hline Student & 222 & $(50.9)$ \\
\hline Intern & 112 & $(25.7)$ \\
\hline Clinical faculty & 74 & $(17.0)$ \\
\hline Nurse & 20 & $(4.6)$ \\
\hline Cleaner & 8 & $(1.8)$ \\
\hline \multicolumn{3}{|l|}{ Dental personnel's hepatitis B antibody titer } \\
\hline Antibody titer protective* & 332 & $(76.1)$ \\
\hline Antibody titer not protective, or not vaccinated & 46 & $(10.6)$ \\
\hline Missing data & 58 & $(13.3)$ \\
\hline \multicolumn{3}{|l|}{ Instruments causing the injuries } \\
\hline Sharp injuries (high risk instruments) ${ }^{\dagger}$ & 190 & $(43.6)$ \\
\hline Sharp injuries (low risk instruments) $)^{\ddagger}$ & 211 & $(48.4)$ \\
\hline Splash injuries & 24 & $(5.5)$ \\
\hline Bites & 3 & $(0.7)$ \\
\hline Not reported & 8 & (1.8) \\
\hline \multicolumn{3}{|l|}{ Time of injury } \\
\hline While treating & 337 & (77.3) \\
\hline While cleaning & 95 & $(21.8)$ \\
\hline Not reported & 4 & $(0.9)$ \\
\hline \multicolumn{3}{|c|}{$\begin{array}{l}\text { *Protective antibody titer was defined as } 10 \mathrm{IU} / \mathrm{L} \text { or more, } \\
\text { †Instruments classified as high risk are: local anesthesia needle, suture } \\
\text { needle, elevator, forceps, scaler tip, blade, matrix band, needle holder, } \\
\text { ‡Instruments classified as low risk are: irrigation needle, endodontic file, } \\
\text { Gates Gliden, probe (explorer) amalgam carver, plastic instrument, wax } \\
\text { knife, orthodontic wire, bur, finishing disk. }\end{array}$} \\
\hline
\end{tabular}

Eight patients were found positive for $\mathrm{HBsAg}$, representing $2.15 \%$ of all patients involved in sharp/ splash injuries. As with $\mathrm{HCV}$, this result shows that HBV positivity is higher than what has been previously reported for the UAE as $0.7 \% .{ }^{4}$ This too can be explained by the fact that all the patients with positive $\mathrm{HBs} A g$ were of Pakistani nationality. A similar prevalence was reported by Jafri et $\mathrm{al}^{15}$ who found that $1.8 \%$ of Pakistani children were tested positive for HBsAg.

According to Federal Law No. 14 (2009), residents of the UAE are required to undertake screening for tuberculosis, leprosy, syphilis, HCV, HBV and HIV upon issuing and renewing the residency visa. Residents who are found to be positive for HBV and/or HCV are entitled for work in all occupations except those involving direct contact with humans, such as child care workers, house maids, hairdressers, and healthcare professionals. The HIV positive cases are denied residency and are immediately deported. ${ }^{16}$

The setting of this study was a teaching dental hospital offering free dental treatment. The majority of patients attending this facility are in low-income professions, such as construction workers, drivers and landscapers, who have been granted residency visas and work permits despite positive $\mathrm{HBV}$ and/or HCV screening results, which explains the higher prevalence in comparison to what was previously reported. ${ }^{4}$ The immediate deportation of HIV positive cases explains their non-existence among our study population. 
Table 5 - Hepatitis B vaccination status according to sex and the provider's professional status. More females were vaccinated in comparison to males, and cleaners showed very low vaccination rate in comparison to the other dental personnel.

\begin{tabular}{|c|c|c|c|c|c|c|c|}
\hline \multirow{2}{*}{ Vaccination status ${ }^{\ddagger}$} & \multicolumn{2}{|c|}{ Gender* } & \multicolumn{5}{|c|}{ Dental personnel's professional status $\dagger$} \\
\hline & Males & Females & Student & Intern & Faculty & Nurse & Cleaner \\
\hline $\begin{array}{l}\text { Vaccinated } \\
\mathrm{n}=332(87.7 \%)\end{array}$ & $57(78.1)$ & $257(90.2)$ & $173(88.2)$ & $96(94.1)$ & $51(86.4)$ & $11(73.3)$ & $1(16.7)$ \\
\hline $\begin{array}{l}\text { Not vaccinated } \\
\mathrm{n}=46(12.2 \%)\end{array}$ & 16 (21.9) & $30 \quad(9.8)$ & $23(11.7)$ & $6 \quad(5.9)$ & $8(13.6)$ & $4(26.7)$ & $5(83.3)$ \\
\hline
\end{tabular}

The fact that dentistry is associated with frequent use of sharp instruments, which are often contaminated with the patient's saliva and blood, makes this ambulatory healthcare profession one with considerable biological hazard. This was evident in sporadic reports of HBV transmission that was attributed to dental treatments conducted under sub-optimal infection control practices. ${ }^{10-12}$ Although HBV possesses greater infectivity and longer survival in comparison to HCV, a higher prevalence of $\mathrm{HCV}$ is observed in many regions, including the Middle East as a result of worldwide adoption of $\mathrm{HBV}$ vaccination. ${ }^{17}$

The detection of HCV in saliva and oral mucosa constantly raises concerns about its infectivity to dental personnel. ${ }^{18,19}$ The likelihood of HCV transmission following percutaneous exposure was estimated to range from 0 to $7 \% .{ }^{20}$ Westermann et $\mathrm{al}^{21}$ found that healthcare workers are significantly more likely to be $\mathrm{HCV}$ positive in comparison to population-based controls, with dentists having the highest odds ratio among all other healthcare professionals. This supports other studies which showed a relatively high prevalence of HCV among dentists $(0.7 \%)$ and oral surgeons $(2 \%)$ in North America. ${ }^{22}$ Klein et $\mathrm{al}^{23}$ found that dentists with positive $\mathrm{HCV}$ antibodies (1.75\%) were engaged more in treating I.V. drug users than those who were seronegative, which infers a patient-to-dentist transmission of the virus.

On the other hand, Eskandarani et $\mathrm{al}^{24}$ found that blood-borne viruses (HBV, HCV and HIV) did not transmit from 85 known contagious source patients to injured healthcare workers, despite the commonality of injuries.

In this study, none of the 3 healthcare providers injured with instruments used on HCV-RNA positive patients seroconverted after a 6-month follow-up. In one of those 3 cases, the instrument causing the injury was a local anesthesia needle (high risk sharp instrument), while in the remaining 2 cases the instrument was an irrigation needle (low risk sharp instrument). Although all needles are hollow-bore sharp instruments, irrigation needles do not normally get in direct contact with the patient's blood and saliva, which decreases the likelihood of a viral transmission. All providers injured by HBV positive patients had protective antibody titer against $\mathrm{HBV}$ and hence, transmission to those was not a concern.

The majority of dental personnel in this study $(87.8 \%)$ had protective antibody titer against HBV. The remaining (12.2\%) were not protected against this virus either because they did not receive the vaccine, or they did but did not seroconvert. A decline in seroprotection with time has also been suggested, necessitating the use of a booster dose. ${ }^{25,26}$ Cross tabulation against the dental personnel's gender and professional status showed low vaccination rate in males $(p=0.005)$ and cleaning staff $(p<0.000)$. Surveys on dentists from regional countries such as Iran, found a vaccination rate of $94.3 \%$, and India, with a vaccination rate of $85.4 \% .{ }^{27,28}$ The relatively low vaccination rate in this study, despite the availability of the vaccine, warrants more rigid policies mandating early vaccination before engaging in treating patients.

Study limitations. The study sample was confined to dental patients, and -in being a retrospective studywas associated with some incomplete sharp and splash injury records. For those 2 reasons, the generalizability of the outcomes of this study ought to be taken with limitations. Larger cross-sectional studies are needed to establish the prevalence of viral hepatitis at the national level.

In conclusion, the prevalence of $\mathrm{HBV}$ and $\mathrm{HCV}$ in the UAE was found to be higher than what was previously reported, which can be attributed to the study population in being expatriates in low-income 
occupations. The fact that our sample represents unanticipated incidental cases of sharp, splash and bite injuries is a factor which favors randomness in selection, and hence strengthens the outcomes of this study.

Acknowledgment. The author is thankful to Dr. Ali Qabbani and Nurse HoneyBeth Berami for their valuable role in archiving and following up incidents of sharp and splash injuries, and to the Language Institute of the University of Sharjah (www.sharjah.ac.ae) for their English language editing.

\section{References}

1. Global Hepatitis Report 2017. Geneva: World Health Organization; 2017. Available from: http://apps.who.int/iris/ bitstream/10665/255016/1/9789241565455-eng.pdf?ua=1

2. Schweitzer A, Horn J, Mikolajczyk RT, Krause G, Ott JJ. Estimations of worldwide prevalence of chronic hepatitis $\mathrm{B}$ virus infection: a systematic review of data published between 1965 and 2013. Lancet 2015; 386: 1546-1555.

3. Mohd Hanafiah K, Groeger J, Flaxman AD, Wiersma ST. Global epidemiology of hepatitis $C$ virus infection: new estimates of age-specific antibody to HCV seroprevalence. Hepatology 2013; 57: 1333-1342.

4. Mohamoud YA, Riome S, Abu-Raddad LJ. Epidemiology of hepatitis $\mathrm{C}$ virus in the Arabian Gulf countries: Systematic review and meta-analysis of prevalence. Int J Infect Dis 2016; 46: 116-125.

5. Molla S, Munshea A, Nibret E. Seroprevalence of hepatitis B surface antigen and anti HCV antibody and its associated risk factors among pregnant women attending maternity ward of Felege Hiwot Referral Hospital, northwest Ethiopia: a crosssectional study. Virol J 2015; 12: 204.

6. Baha W, Foullous A, Dersi N, They-they TP, El alaoui K, Nourichafi N, et al. Prevalence and risk factors of hepatitis B and $\mathrm{C}$ virus infections among the general population and blood donors in Morocco. BMC Public Health 2013; 18: 13-50.

7. Özer B, Seydaoğlu G, Özşahın AK, Demırhındı H. Risk factors for higher anti-HCV positivity in a border city in southern Turkey with unique population characteristics. Turk J Gastroenterol 2012; 23: 574-579.

8. Barakat SH, El-Bashir N. Hepatitis C virus infection among healthy Egyptian children: prevalence and risk factors. $J$ Viral Hepat 2011; 18: 779-784.

9. Guadagnino V, Stroffolini T, Rapicetta M, Costantino A, Kondili LA, Menniti-Ippolito F, et al. Prevalence, risk factors, and genotype distribution of hepatitis $C$ virus infection in the general population: a community-based survey in southern Italy. Hepatology 1997; 26: 1006-1011.

10. Shaw FE Jr, Barrett CL, Hamm R, Peare RB, Coleman PJ, Hadler SC, et al. Lethal outbreak of hepatitis B in a dental practice. JAMA 1986; 255: 3260-3264.

11. Redd JT, Baumbach J, Kohn W, Nainan O, Khristova M, Williams I. Patient-to-patient transmission of hepatitis B virus associated with oral surgery. J Infect Dis 2007; 195: 1311-1314.

12. Radcliffe RA, Bixler D, Moorman A, Hogan VA, Greenfield VS, Gaviria DM, et al. Hepatitis B virus transmissions associated with a portable dental clinic, West Virginia, 2009. J Am Dent Assoc 2013; 144: 1110-1118.
13. Hutin YJ, Harpaz R, Drobeniuc J, Melnic A, Ray C, Favorov $\mathrm{M}$, et al. Injections given in healthcare settings as a major source of acute hepatitis B in Moldova. Int J Epidemiol 1999; 28 : 782-786.

14. Kane A, Lloyd J, Zaffran M, Simonsen L, Kane M. Transmission of hepatitis B, hepatitis $\mathrm{C}$ and human immunodeficiency viruses through unsafe injections in the developing world: model-based regional estimates. Bull World Health Organ 1999; 77: 801-807.

15. Jafri W, Jafri N, Yakoob J, Islam M, Tirmizi SF, Jafar T, et al. Hepatitis B and C: prevalence and risk factors associated with seropositivity among children in Karachi, Pakistan. BMC Infect Dis 2006; 23: 101.

16. Federal Law No. 14 (year 2014) Regarding the Control of Infectious Diseases. Available from URL: https://www.dha.gov. ae/ar/HealthRegulation/Pages/FederalLaws.aspx

17. Bond WW, Favero MS, Petersen NJ, Gravelle CR, Ebert JW, Maynard JE. Survival of hepatitis B virus after drying and storage for one week. Lancet 1981; 1: 550-551.

18. Hermida M, Ferreiro MC, Barral S, Laredo R, Castro A, Diz Dios P. Detection of HCV RNA in saliva of patients with hepatitis C virus infection by using a highly sensitive test. $J$ Virol Methods 2002; 101: 29-35.

19. Carrozzo M, Quadri R, Latorre P, Pentenero M, Paganin S, Bertolusso G, et al. Molecular evidence that hepatitis C virus replicates in the oral mucosa. J Hepatol 2002; 37: 364-369.

20. Younai FS. Health care-associated transmission of hepatitis B \& C viruses in dental care (dentistry). Clin Liver Dis 2010; 14: 93-104.

21. Westermann C, Peters C, Lisiak B, Lamberti M, Nienhaus A. The prevalence of hepatitis $\mathrm{C}$ among healthcare workers: a systematic review and meta-analysis. Occup Environ Med 2015; 72: 880-888.

22. Thomas DL, Gruninger SE, Siew C, Joy ED, Quinn TC. Occupational risk of hepatitis $\mathrm{C}$ infections among general dentists and oral surgeons in North America. Am J Med 1996; 100: 41-45.

23. Klein RS, Freeman K, Taylor PE, Stevens CE. Occupational risk for hepatitis $\mathrm{C}$ virus infection among New York City dentists. Lancet 1991; 338: 1539-1542.

24. Eskandarani HA, Kehrer M, Christensen PB. No transmission of blood-borne viruses among hospital staff despite frequent blood exposure. Dan Med J 2014; 61: A4907.

25. Chaouch H, Hachfi W, Fodha I, Kallala O, Saadi S, Bousaadia A, et al. Impact and long-term protection of hepatitis $B$ vaccination: 17 years after universal hepatitis B vaccination in Tunisia. Epidemiol Infect 2016; 18: 1-11.

26. Li H, Li GJ, Chen QY, Fang ZL, Wang XY, Tan C, et al. Long-term effectiveness of plasma-derived hepatitis $\mathrm{B}$ vaccine 22-28 years after immunization in a hepatitis B virus endemic rural area: is an adult booster dose needed? Epidemiol Infect 2017; 145: 887-894.

27. Ahmad Akhoundi MS, Momeni N, Norouzi M, Ghalichi L, Shamshiri AR, Alavian SM, et al. Prevalence of blood-borne viruses among Iranian dentists: Results of a national survey. Int J Occup Med Environ Health 2015; 28: 593-602.

28. Reddy V, Bennadi D, Kshetrimayum N, Reddy CV, Satish G, Kura U, et al. Prevalence of hepatitis B vaccination among oral health care personnel in Mysore city, India. Oral Health Dent Manag 2014; 13: 652-655. 